\title{
Chapter 7 \\ Green Manufacturing: Carbon \\ Emissions Reduction Roadmap of Carbon Intensive Sectors
}

\begin{abstract}
The implementation of green manufacturing is a key step for China to achieve carbon neutrality. According to China Emission Accounts and Datasets (CEADs), energy-intensive industries such as steel, cement, oil and gas, chemicals and non-ferrous metals, were responsible for about $36 \%$ of China's total carbon emissions in 2017. This chapter analyzes changes in the green premiums of the steel, cement, non-ferrous metals, general manufacturing industries, as well as oil, gas and chemicals at different stages of development to explore how manufacturing sectors may become carbon neutral. Having analyzed total carbon emissions and green premiums of various sectors, we conclude that the higher the proportion of carbon emissions from internal production processes is, the higher green premiums are and the more difficult it is to reduce carbon emissions. As thermal power may be gradually replaced by renewable energy sources, we believe emissions from power consumption may decline sharply. If emissions of an industry mainly come from internal production processes rather than electricity consumption, such an industry would need to upgrade technological routes or adopt carbon capture technologies to reduce emissions, which means a higher green premium. We believe 2021-2030 may be the toughest period for emission cuts in manufacturing industries. While it is relatively easier to cut emissions from power generation, electricity consumption is not the main culprit for carbon emissions in most energy-intensive industries. Therefore, these industries may face both financial and technological problems in cutting emissions, especially in the early stages before 2030. Based on the direct emissions from internal production processes (without taking into account emissions from power consumption), we estimate a green premium ratio (i.e., magnitude of cost increase to achieve net-zero emissions) of $21 \%$ for steel, $151 \%$ for cement, $4 \%$ for aluminum, $61 \%$ for chemicals, and $8 \%$ for oil and gas sectors in 2019. Earnings of general manufacturing industries may decline about $3 \%$ if the green premium is taken into account. We believe these industries will need supportive public policies in this period to help them solve their problems, complete technology upgrading, and find a feasible path for emission cuts. During the period from carbon peak to carbon neutrality, we believe energy-intensive industries may face much milder pressure on emission reduction as these industries can finally develop a feasible and affordable roadmap for emission cuts. With low-carbon transition and falling aggregate supply and demand of some energy-intensive industries, we believe the green premium ratio
\end{abstract}


(based on emissions from internal production processes) may decline to $6.7 \%$ for steel, $67.5 \%$ for cement, $2.0 \%$ for aluminum, $-0.8 \%$ for chemicals, and $-3.3 \%$ for oil and gas sectors in 2060, much lower than the current levels.

\subsection{Cost of Zero Emissions: Analyzing the Carbon Neutrality Roadmaps of Manufacturing Industries from Perspective of Green Premiums}

This chapter analyzes changes in the green premiums of the steel, cement, nonferrous metals, oil and gas, chemicals, and general manufacturing industries at different developing stages to explore how manufacturing sectors might become carbon neutral.

First of all, under the current technological conditions, the additional cost of achieving zero emissions in major manufacturing industries is very high. Therefore, it is difficult to achieve carbon neutrality in manufacturing sectors overnight. Reducing carbon emissions must be conducted progressively at a cost that the industry itself and downstream sectors can afford. The current carbon emissions of energy-intensive manufacturing industries can mainly be classified into two categories: electricity and non-electric emissions. The electricity category can achieve zero emissions by converting thermal power into low-carbon electricity such as wind power and photovoltaic power generation, resulting in lower additional costs. However, it is difficult for the non-electric category to achieve zero emissions without the help of carbon capture technology, and achieving zero emissions is costly. Overall, apart from the general manufacturing industry, the current green premium level of key manufacturing industries is generally high. We estimate that in order to achieve zero emissions with direct and indirect emissions reduction method, the green premium ratios of the steel, cement, electrolytic aluminum, basic chemical, and petrochemical industries are $22 \%, 156 \%, 34 \%, 66 \%$, and $8 \%$, respectively. The profit of the general manufacturing industry will drop by about $3 \%$ from the level of 2019. If considering the nonelectric emissions only, the green premiums of steel, cement, electrolytic aluminum, basic chemicals, and petrochemicals in 2019 were $21 \%, 151 \%, 4 \%, 61 \%$, and $8 \%$, respectively. Most industries will not be able to afford the internalized carbon neutralization costs without passing on rising costs to downstream. The cement industry, which has the highest green premium, would even need to pay about 3 years of net profit to achieve zero emissions at this point. Therefore, it is difficult to achieve carbon neutrality in manufacturing industry now. It needs to be done step by step, and public policy tools should be used to guide enterprises to and promote technological innovation. Various industries need to develop practical emission reduction paths based on actual conditions of their industries and downstream sectors (see Fig. 7.1).

Second, we discuss whether various industries can use existing technological innovations and available public policy tools to explore an optimal emission reduction path. The manufacturing industry still needs to use policy tools such as supply restriction in the early stages of carbon peak, while after carbon peak is reached, 


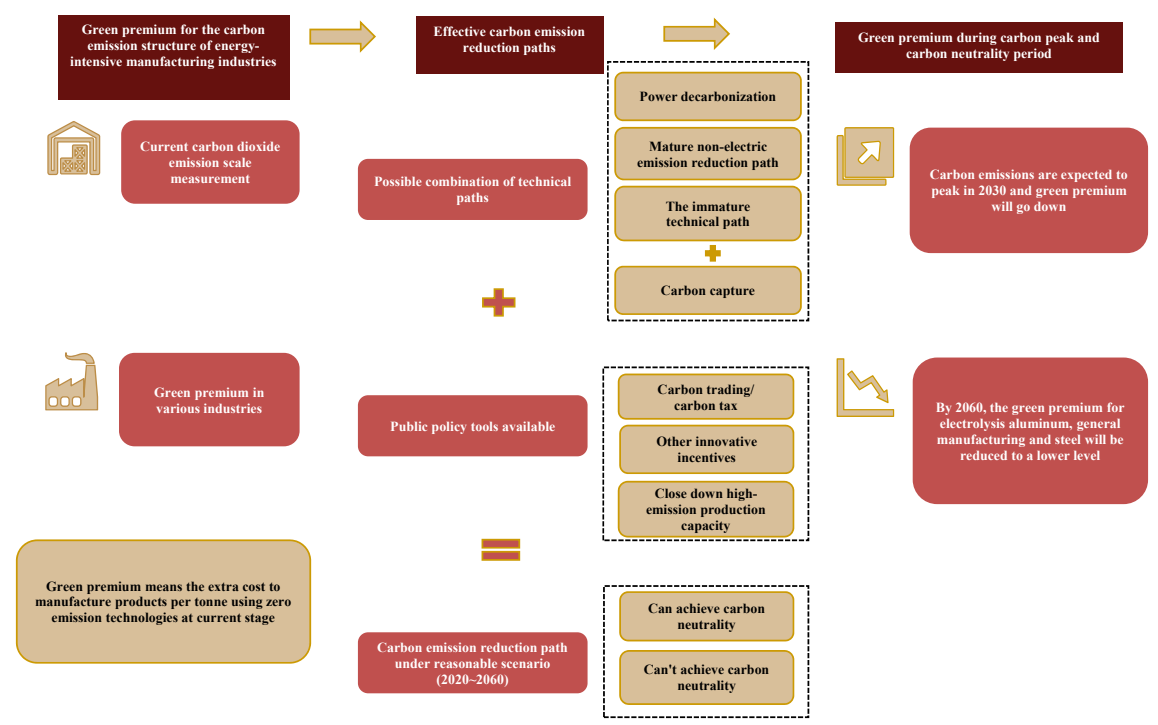

Fig. 7.1 A mind map for green manufacturing. Source CICC Research

the mature carbon reduction technology and the natural decline of industry production and sales will become important drivers of emission reduction. First, since the main sources of carbon emissions of aluminum and general manufacturing industries come from electricity, it is the least difficult to reduce emissions. Carbon peak and reduction of carbon emissions can be achieved through imposing proper production limits as well as restricting the upper limit of production capacity at the initial stage. As the proportion of thermal power gradually reduces to zero, we expect electricityrelated carbon emissions to be close to zero by 2060 . Second, the steel industry can convert high-emission blast furnace production capacity into low-emission electric arc furnaces (this technology is mature but faces constraints from the availability of raw materials. We expect the proportion of steel production using electric arc furnaces to reach $60 \%$ by 2060). The adoption of low-carbon transformation by blast furnaces could be another solution, but it is not yet at a mature stage. In the early stages of carbon peak, certain restrictions on production capacity and output still need to be imposed. In the middle and later stages, public policy tools, such as carbon tax, carbon trading mechanism, and pilot subsidy mechanism can be used to encourage enterprises to reduce emissions and achieve industrial upgrading. Third, under the current conditions, as cement and chemical industries lack mature technologies to significantly reduce carbon emissions, they are highly dependent on carbon capture technologies. The early carbon peak mainly relies on restrictions on production capacity and output. It is also necessary to adopt policies to encourage 
enterprises to carry out technological transformation to reduce emissions.

In order to quantify the effectiveness of emission reductions, we also forecast the carbon emissions of various industries from 2020 to 2060 under reasonable deductions on future circumstances. This shows that most industries are expected to reach peak carbon emissions ahead of schedule and achieve carbon neutrality with the aid of carbon capture in 2060. Other than prompting technologies upgrading and limiting production, forcing retirement of outdated production methods could also be an important tool. The impact on these industries is similar to supply-side reforms. Based on our estimates, most industries are likely to achieve carbon peak around 2030 given the policies above. From 2030 to 2060, the growth of production and sales in some industries might slowdown or even decline. After the new technology reaches a mature stage, the technological transformation of enterprises will be promoted on a larger scale, which will lead to reduction in carbon emissions per tonne of products. By 2060, the steel, cement, aluminum, and the chemical industries are expected to reduce carbon emissions by $79 \%, 78 \%, 90 \%$, and $63 \%$ compared to 2019 levels, respectively, without the use of carbon capture technology. As the cost of carbon capture drops sharply, the technology will be used to achieve carbon neutrality, and become affordable for these industries. As a result, these industries are expected to become carbon neutral. We expect the general manufacturing industry to fully achieve carbon neutrality without the use of carbon capture technology by 2060 .

Finally, we calculate the green premiums of various industries during the carbon peak (2030) and carbon neutrality (2060) periods under reasonable circumstances to observe whether the burden of achieving carbon neutrality on enterprises will decrease significantly over time and lead to a positive conclusion. For industries in which carbon emissions are mainly derived from electricity, namely aluminum and general manufacturing, and industries that have mature paths to significantly reduce carbon emissions, namely steel, their green premiums should decline sharply and will reach an affordable level, or even close to zero. For industries that have not yet established a mature emission reduction path, such as cement and chemical, the green premium will also fall sharply. Companies can carry cost pressures through appropriate price increases.

In summary, manufacturing industries will likely face the greatest challenge in reducing emissions in the following 10 years, and the pressure may be reduced significantly after that. In these 10 years, the industries face both technical difficulties and cost dilemmas. To achieve carbon neutrality under current conditions, all high-energy-consuming manufacturing industries except for general manufacturing will face substantial increases in costs and potentially heavy losses. Therefore, in the early stages of reducing carbon emissions, it is necessary to take step-by-step approach, and the government should provide strong support to enterprises using public policy such as carbon trading mechanisms, pilot subsidies, and production restrictions to help overcome difficulties. After 2030, the green premiums of various industries are likely to decline sharply. In 2060, the green premium ratios of steel, cement, aluminum, chemicals, and petrochemicals will be $6.7 \%, 67.5 \%, 2.0 \%$, $-0.8 \%$, and $-3.3 \%$, respectively, all of which will drop significantly compared to 
2019. Therefore, with technological innovation and policy support, manufacturing industries will eventually find a reasonable and affordable way to reduce emissions.

\subsection{Steel Industry: Mature Emission Reduction Path with Electric Arc Furnace Gradually Demonstrating Advantages}

\subsubsection{Industry Green Premium: Cost for the Steel Industry to Achieve Carbon Neutrality at the Current Stage}

The steel industry is the industry with the largest carbon emissions in China industrial sectors and a pillar industry for economic and social development. Therefore, carbon neutrality in the steel industry is crucial to China carbon neutrality. We estimate carbon emissions from China's steel industry might reach 1.54bn tonnes in 2019, accounting for $47 \%$ of carbon emissions from industrial sectors and $18 \%$ of China's total carbon emissions. The steel industry is the largest carbon emitter among all industrial sectors.

High carbon emissions have led to a relatively high level of green premium in the steel industry. We estimate that production of one tonne of steel using the blast furnace process emits 1.68tonnes of carbon dioxide, of which 1.42tonnes comes from internal production processes and 0.26tonnes from electricity consumption. About 0.4tonnes of carbon dioxide is emitted for every tonne of steel produced using the electric furnace process. The main raw materials are iron ore and coke for blast furnace process and are steel scraps for electric furnace process. Having considered electricity consumption, we estimate the green premium for each tonne of crude steel produced is Rmb695, corresponding to a $22 \%$ increase of pre-carbon neutrality costs. It also implies an industry-wide green premium of Rmb690bn. Given that the average annual total profit of the steel industry was Rmb223bn in the past 10 years, the green premium of the steel industry in 2019 was approximately equivalent to 3 years of total profit for the steel industry.

The steel industry cannot fully internalize the costs of achieving carbon neutrality. We estimate that if the steel industry were to reach carbon neutral, and that all of the related costs were internalized in 2019 , the cost to the steel industry would be Rmb690bn with a corresponding increase of Rmb695/tonne for crude steel. Together with oversupply and product homogeneity issues, we believe the steel industry will not be able to fully internalize the entire cost to achieve carbon neutrality. Without government guidance and support, it is difficult for the steel industry to achieve carbon neutrality on its own. 


\subsubsection{Technology Roadmaps for Carbon Emissions Reduction in the Steel Industry}

Replacing traditional blast furnace with electric arc furnace is the most effective and economical technology roadmap. Electric arc furnace can significantly reduce carbon emissions with lower per unit costs and shorter production cycles. Moreover, China's current dependence on imported iron ore is as high as $90 \%$, making the switch from blast furnaces to electric arc furnaces an essential measure to help China gradually reduce its dependence on imported coking coal and iron ore. It would also help China secure the supply of raw materials in important industrial sectors. With the target of carbon neutrality, we expect China's demand for coking coal and iron ore to decline by $60 \%$ by 2030 and by $70 \%$ by 2060 thanks to the rising supply of steel scraps, close to the current level in the US and Europe. We expect China's demand for coking coal and iron ore to drop by $60 \%$ and $70 \%$ as of 2030 and 2060, which will help China achieve independence in raw materials.

China is currently exploring new technologies to develop a more environmental friendly metallurgy industry. One path is hydrogen metallurgy and the other is non-hydrogen direct reduced iron. Hydrogen metallurgy can greatly reduce carbon emissions of blast furnaces, but it remains too early for large-scale applications. Non-hydrogen direct reduced iron technology is a mature technology which can significantly reduce carbon emissions from blast furnaces. However, its applications in China are constrained by gas sources and equipment. We believe China's steel industry needs to continuously explore new technologies to reduce carbon emissions. We see three main potential approaches (1) green energy; (2) separation and recycling of carbon dioxide from blast furnaces; and (3) recycling of carbon monoxide in blast furnace gas.

We suggest that the steel industry adopt emissions trading mechanisms to help reduce carbon emissions with the current emissions reduction strategies. Reduction of carbon emissions in the steel industry requires decades of continuous effort, and all measures targeting the goal should be implemented progressively. In the early stages, it is necessary to impose certain restrictions on production capacity and output to reach carbon peak. In the later stages, we suggest using public policy tools to encourage enterprises to reduce emissions independently. On the one hand, leading steelmakers may be more willing to switch to electric arc furnaces as the cost of electricity can be reduced to strengthen their cost advantages. On the other hand, the emissions trading mechanisms can generate additional revenue.

\subsubsection{Lowering the Green Premium: Will the Steel Industry Achieve Carbon Peak and Carbon Neutrality as Planned?}

Due to the continuous development of electric arc furnace technology and the policy constraints, the steel industry is expected to achieve carbon peak before 2030 . 
However, due to limited scrap steel resources, electric arc furnaces cannot completely replace blast furnaces. Carbon neutrality can only be achieved with the support of carbon capture. We believe carbon emission reduction will be driven by two factors: (1) a sharp decline in demand for construction steel after China's urbanization rate gradually approaches $75 \%$, which will drive the production of steel down to $0.88 \mathrm{bn}$ tonnes in 2030 and 0.65bn tonnes in 2060 (Fig. 7.2); and (2) the proportion of electric arc furnaces rising to $30 \%$ and $60 \%$ in 2030 and 2060. We estimate carbon dioxide emissions may reach $960 \mathrm{mn}$ tonnes in 2030 , reaching carbon peak ahead of schedule, and we expect carbon dioxide emissions to fall further to $320 \mathrm{mn}$ tonnes in 2060, about $79 \%$ below the 2019 level. The steel industry is expected to achieve carbon neutrality when the cost of carbon capture technology becomes affordable.

By 2060, the steel industry is expected to fully internalize the cost of carbon neutrality, and to achieve zero carbon emissions. Taking electricity consumption into account, we estimate green premium for the steel industry (mainly the cost of carbon capture) are Rmb695, Rmb270, and Rmb115 per tonne of steel in 2019, 2030, and 2060, respectively (Fig. 7.3). With carbon emissions falling to 320mn tonnes industry-wide, the overall green premium for the steel industry may drop to $\mathrm{Rmb} 74.4 \mathrm{bn}$. As the proportion of green premium in the cost of steel manufacturing continues to drop, we expect that the cost of carbon neutralization can be internalized and the industry can achieve zero carbon emissions by 2060 .

\subsection{Cement Industry: Achieving Carbon Neutrality is Difficult. Demand and Cost of Carbon Capture are the Key}

\subsubsection{Industry Green Premium: Cost of Achieving Carbon Neutrality at Current Stage for Cement Industry}

The cement industry is among the industries with the highest level of carbon emissions. We estimate that China's cement industry emitted $1.37 \mathrm{bn}$ tonnes of carbon dioxide emissions in 2019, accounting for $14 \%$ of China's total carbon emissions. Production of one tonne of cement emits 0.6 tonnes of carbon dioxide, with 0.36 tonnes from limestone production, 0.18 tonnes from coal combustion and 0.05 tonnes from electricity consumption.

The cement industry currently has no mature emission reduction method other than carbon capture. However, it is costly to achieve zero emissions through carbon capture. Currently, 99\% of the production lines in the cement industry are dryprocess clinker production lines and the technology system is mature. In the cement manufacturing process, carbon dioxide generated by electricity can be eliminated by outsourcing non-thermal power, and carbon dioxide generated from non-electric processes needs to be absorbed by carbon capture. We estimate that the carbon capture cost was about Rmb500 per tonne of cement in 2019. Assuming the cement 


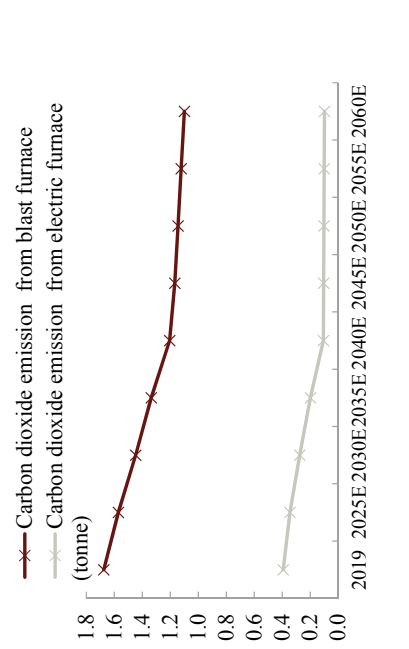

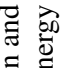

후 뙤

ชำ

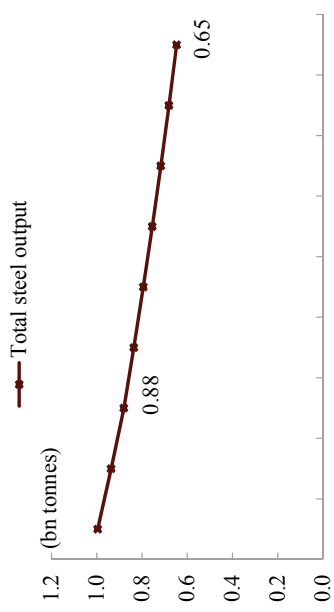

$\overrightarrow{5}$

过

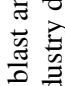

ㅎ․․․

.ㄹ

胥

ฮ $\cong$

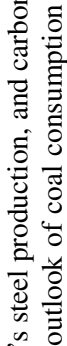

苛

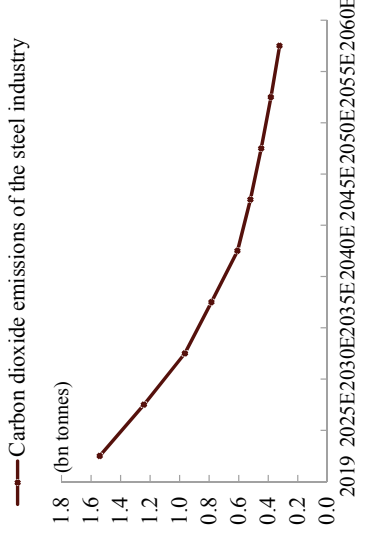

空

药

ญ

츨

.

อิ

$\frac{1}{1}$

을 을

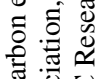

U

ํㅛㄹ 


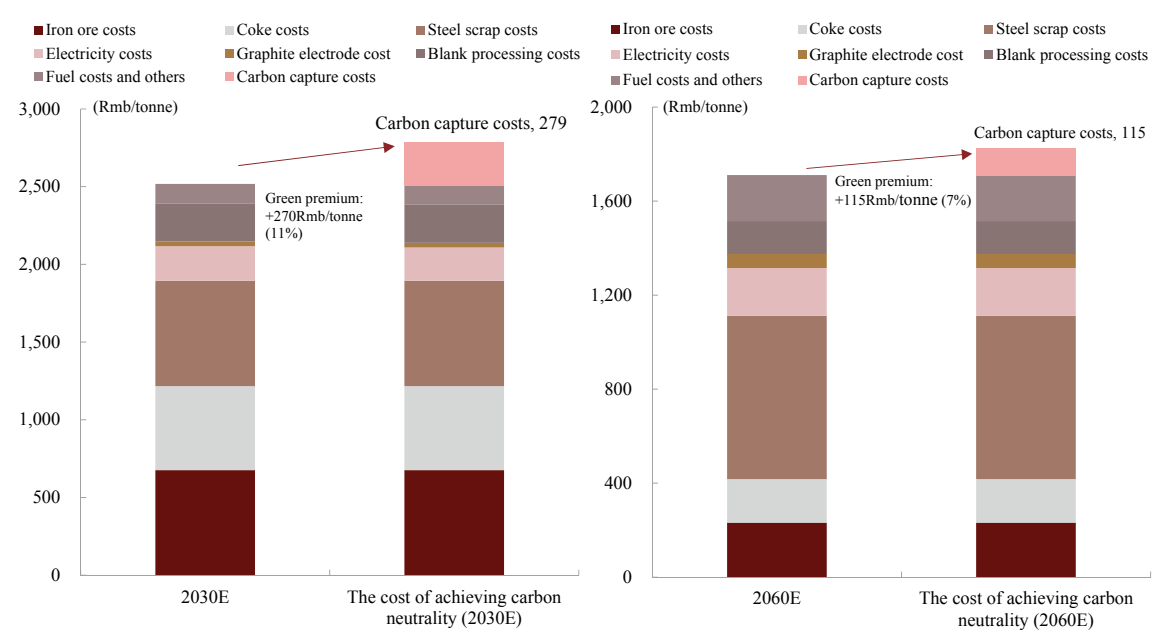

Fig. 7.3 Green premiums for leading steelmakers to achieve carbon neutrality through carbon capture in 2030 and 2060. Source Global status of CCS 2019, European Zero Emission, Technology and Innovation Platform, the National Petroleum Council, GCCS, Wind Info, CICC Research

industry was operating at net zero emissions in 2019, we estimate the green premium at Rmb278/tonne, implying an industry-wide green premium of Rmb647.8bn, three times the profit in 2019.

The cement industry cannot afford to internalize the full cost of achieving carbon neutrality. We estimate that if the cement industry were carbon neutral, and all related costs were internalized in 2019, the increase in total cost to the industry would have been Rmb650bn. The profit of the cement industry in 2019 reached a historical high of about Rmb186.7bn, implying net profit of about Rmb80 per tonne of cement. The total profit in 2015 to 2016 was only Rmb30 to 50bn, implying net profit of Rmb1525 per tonne. Therefore, the cement industry will not be able to withstand this cost pressure even during high earning periods unless it can pass costs on to downstream participants. If cement manufacturers manage to increase their prices, the real estate, infrastructure, and rural construction sectors would likely see much higher costs.

\subsubsection{Technology Roadmaps for Carbon Emissions Reduction in the Cement Industry}

The cement industry has very limited ways to reduce carbon emissions per unit. Based on our discussions with industry associations and cement companies, it is difficult for the cement industry to significantly reduce per unit carbon emissions. There are only a few ways to reduce carbon emissions at a marginal level, mainly including: 
First, reducing coal and electricity consumption through technological upgrading and renewable energy. The cement industry can reduce cement power consumption by one-third and coal consumption by more than $10 \%$ through waste heat power generation and use of alternative fuels.

Second, pushing forward decarbonization of the power sector. The cement industry mainly uses thermal power currently. However, as thermal power is gradually replaced by non-carbon energy sources or coal-fired power plants using carbon capture technology, we expect the electricity used in the cement industry to gradually become decarbonized.

Third, using low-carbon raw materials. The use of low-carbon alternative raw materials such as desulfurized gypsum and electric arc furnace slag can slightly reduce the carbon emissions caused by the decomposition of limestone.

The cement industry mainly relies on carbon capture and storage to achieve carbon neutrality. We expect these three technological pathways to help the industry gradually reduce the unit energy consumption. If technological upgrading can be achieved to reach a theoretically maximum level, the consumption of electricity, coal and raw materials could decline by $22 \%, 15 \%$ and $30 \%$, respectively, for each tonne of cement by 2060 . That said, carbon emissions per tonne of cement may remain as high as 0.4 tonnes in 2060 . Therefore, the two main ways to achieve carbon neutrality in the cement industry in the future will still be technological transformation to reduce per unit carbon emissions and carbon capture. The current cost of carbon capture is high and it is likely to be relatively expensive in the future even with technological upgrading.

In terms of policy guidance, carbon allowance can be restricted in the short term and carbon tax or carbon trading can be adopted in the long term. Due to the technical difficulty in reducing emissions and high cost of carbon capture in the cement industry, it is difficult to afford the carbon at present. Thus, the cement industry mainly relies on the capacity and output restrictions of cement companies. In the long run, the industry also needs to encourage enterprises to pursue emission reduction through technological transformation by adopting policies such as carbon trading and carbon tax. Both carbon tax and carbon trading are suitable policies for guiding the cement industry to actively reduce emissions. However, compared with carbon tax, carbon trading adopts a flexible market-based mechanism that takes the large differences between profitability in different regions and time periods into account. It also enables companies that make bigger cuts in emissions to obtain some revenue as a reward.

In addition, China may unveil a pilot program that subsidizes and encourages cement manufacturers to use solid waste and waste heat to generate power and use other raw materials to replace limestone. Driven by the carbon trading mechanism and green subsidy policies, companies that actively explore emission reduction plans and focus on energy conservation and emission reduction may receive additional revenue from the sale of carbon indicators, pilot subsidies, and ultimately increase their market share. Meanwhile, companies that find reducing emissions difficult will gradually withdraw from the market and the industry will be further optimized. 


\subsubsection{Lowering the Green Premium: Feasible Paths to Carbon Peak and Carbon Neutrality in the Cement Industry}

The cement industry has not yet found a mature way to achieve carbon neutrality without carbon capture. However, the green premium will gradually decline due to the progress in carbon capture technology. We estimate green premiums, which are mainly the cost of carbon capture in the cement industry, will be Rmb156 and Rmb106 per tonne of cement in 2030 and 2060, respectively, driving up manufacturing cost by $91 \%$ and $64 \%$ (see Fig. 7.4). As the technology advances, the green premium will decline amid the falling carbon capture expenses.

The decline in cement demand is key to the emissions reduction for the cement industry. We expect the cement industry to achieve carbon peak before 2030, and carbon neutrality by 2060 with the support of affordable carbon capture. We also expect that cement demand will decline significantly as the urbanization rate gradually increases. It is estimated that in 2030, domestic cement production will be between 1.9 and 2.0bn tonnes (see Fig. 7.5). By 2060, with reference to global per capita cement consumption, domestic cement demand will be between 760 and $770 \mathrm{mn}$ tonnes. In 2030, the entire industry's carbon emissions will be reduced to $1.07 \mathrm{bn}$ tonnes, which is lower than the current level of carbon emissions, and the cement industry is expected to achieve carbon peak ahead of schedule. In 2060, carbon emissions will be further reduced to $310 \mathrm{mn}$ tonnes, a $77 \%$ decrease from 2019. But without carbon capture, the industry still cannot achieve carbon neutrality. We estimate that due to the decline in total cement production in 2060 , if carbon neutrality in the cement industry is achieved through carbon capture, the overall green premium of the industry will be Rmb80.6bn.
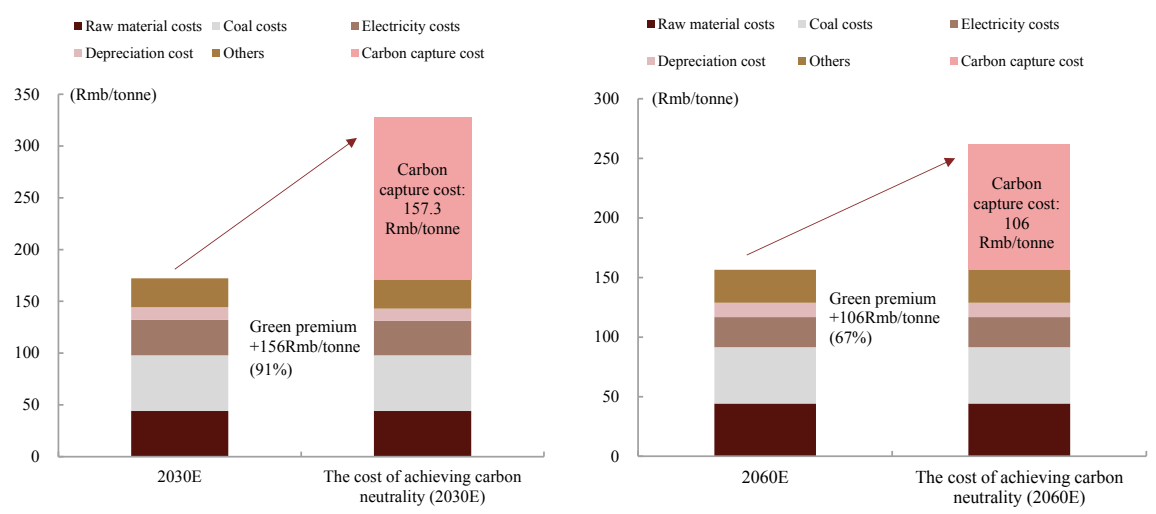

Fig. 7.4 Forecasted green premiums in the cement industry in 2030 and 2060. Source CSR report of ACC, cenews.com.cn, CICC Research 


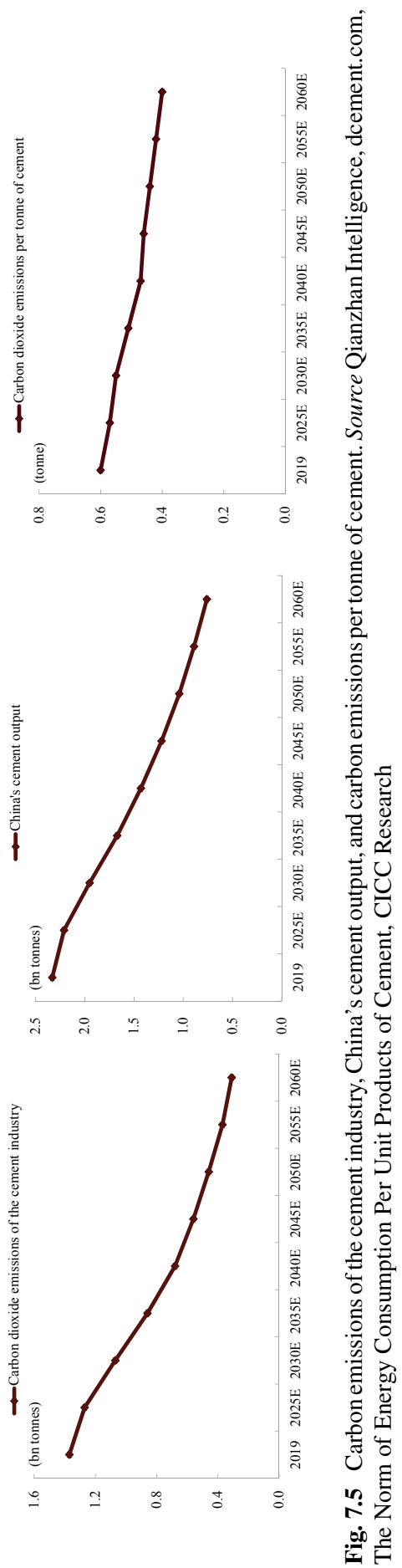




\subsection{Aluminum Industry: The Decarbonization of Electricity is the Key to Carbon Neutrality}

\subsubsection{Industry Green Premium: Cost for the Aluminum Industry to Achieve Carbon Neutrality at the Current Stage}

Aluminum is the main source of carbon emissions in the non-ferrous industry. According to our calculations, carbon emissions from China's non-ferrous metals sector reached $421 \mathrm{mn}$ tonnes in 2019 , with aluminum production accounting for $363 \mathrm{mn}$ tonnes, copper about $11 \mathrm{mn}$ tonnes, lead $16 \mathrm{mn}$ tonnes, and zinc $31 \mathrm{mn}$ tonnes. Since aluminum production makes up $86 \%$ of emissions, making it the largest source of carbon emissions in the non-ferrous metals industry, we will mainly discuss the carbon reduction strategy for the aluminum industry. Based on our estimates, electricity consumption in the process of producing aluminum generates $279 \mathrm{mn}$ tonnes of carbon emissions. In the aluminum industry, electricity consumption contributes $80 \%$ of carbon emissions, and the remaining $20 \%$ are from internal production processes.

Since decarbonized power generation is still costly at this point, the green premium for the aluminum industry is high and cannot be internalized. Zero emissions can be achieved by replacing thermal power with clean energy and using carbon capture to deal with the remaining non-electric carbon emissions. However, the cost of using clean energy and carbon capture technology at the current stage is relatively high. The cost of electricity per tonne of electrolytic aluminum may increase by $50-60 \%$ compared to current levels with a switch to clean energy. We estimate that the green premium is at Rmb3,436 per tonne of aluminum to reach zero emissions in 2019, which may raise costs by $26.9 \%$. The total green premium is Rmb122bn, which is equivalent to 2-3 years' worth of high-level net profit for the industry, or average net profit for 6-7 years.

\subsubsection{Technology Roadmap for Carbon Emissions Reduction in the Aluminum Industry}

The decarbonization of electricity is the key to reducing emissions in the aluminum industry. Decarbonization of electricity can reduce the industry's carbon emissions by $80 \%$, and the remaining non-electricity carbon emissions need to wait for the cost of carbon capture to be lower. The production process of aluminum is "bauxite $\rightarrow$ alumina $\rightarrow$ electrolytic aluminum". The "bauxite $\rightarrow$ alumina" process mainly results in non-electric carbon emissions, accounting for $20 \%$ of the carbon emissions. Given that $90 \%$ of the current production has adopted a low-carbon process (Bayer 
$\operatorname{method}^{1}$ ), process optimization can only marginally reduce the per unit carbon emission. Therefore, it requires carbon capture to achieve zero emissions. We estimate that the cost of carbon capture per tonne of alumina in 2019 would be Rmb501, but will drop to Rmb262 by 2060 . The "alumina $\rightarrow$ electrolytic aluminum" process creates carbon emissions by using electricity, accounting for $80 \%$ of the emissions. Zero emissions can be achieved by replacing thermal power with green electricity. We expect green electricity to have lower cost than thermal power electricity in the long run, and this process to achieve carbon neutrality by 2060 .

In the early stages of carbon emission reduction, it is difficult for companies to afford the cost due to the high green premium. In order to meet the carbon peak target, policies need to impose certain restrictions on the supply side. The current policy has implemented a limit on the total carbon emissions of the industry, of which the impact may be similar to the supply-side reforms in 2016-2017. It helps balance supply and demand in the industry, reduce cyclical fluctuations of the industry's profits, and also promotes the development of leading companies.

In the long run, it will become possible to achieve carbon neutrality through technological advancements as the cost of green energy and carbon capture decreases. It is important to use policies to encourage enterprises to reduce electricity consumption, upgrade to green energy, and adopt carbon capture technology. More importantly, the government may use carbon trading or carbon tax mechanisms to strengthen the cost advantages of companies that use less thermal power. Companies with hydro-power or other clean power generation facilities will have notable cost advantages, whereas small companies that do not perform well in emission reduction may be forced out of the market. Considering the sharp profit fluctuations in the aluminum industry (electrolytic aluminum industry has brought profit of less than Rmb200 per tonne in the past 5 years, but could also exceed Rmb2,000 at the highest level) and regional variations, we believe that carbon trading may be more suitable for companies to adjust their production compared to carbon tax, which involves a unified carbon price. In addition to carbon trading, we also recommend using subsidies to encourage enterprises with suitable conditions to develop secondary aluminum, establish their own green power plants, or increase the use of green energy.

\footnotetext{
${ }^{1}$ The main processes for preparing alumina from bauxite are Bayer method, sintering method and hybrid method. Compared with the latter two methods, the Bayer method can reduce carbon emission per tonne of alumina by about $67 \%$ and $49 \%$.
} 


\subsubsection{Lowering the Green Premium: A Feasible Path for Carbon Peak and Carbon Neutrality in the Aluminum Industry}

Based on previous technology roadmaps and public policies, we expect the aluminum industry to achieve carbon neutrality before 2030. Aluminum Corporation of China and Shandong Weiqiao Pioneering Group jointly issued the Joint Proposal for Accelerating the Green and Low-Carbon Development of the Aluminum Industry in early 2021, striving to reach their peak production capacity and output for domestic alumina and electrolytic aluminum during the 14th Five-Year Plan period. It also estimates that the capacity ceiling of the aluminum industry is around $45 \mathrm{mn}$ tonnes. Given that the growth in supply and demand is expected to slow significantly, we expect the aluminum industry to achieve carbon peak before 2030 with the help of new energy. By 2030, we estimate that the total carbon emissions of the aluminum industry will be about $258 \mathrm{mn}$ tonnes, a decrease of $28.9 \%$ from 2019 .

We expect the aluminum industry to achieve carbon neutrality by 2060 with the support of affordable carbon capture technology. Using green electricity in the production process, carbon emissions per tonne of aluminum might be reduced by $80 \%$ compared to the current level. At the same time, the development of carbon capture technology is expected to bring down green premium per tonne of aluminum from Rmb554 to Rmb262. We estimate that the carbon emissions of the electrolytic aluminum industry in 2060 will be about $38 \mathrm{mn}$ tonnes with green premium of only Rmb4.89bn. The green premium can be internalized by the industry and therefore carbon neutrality might be achieved by then.

Green premium for aluminum industry is expected to decline significantly as the cost of green energy and carbon capture declines. Even considering the cost of switching to green energy, the green premium per tonne of the electrolytic aluminum in 2030 and 2060 will be Rmb1,079 and Rmb262, respectively (see Fig. 7.6), which mainly comes from the cost of carbon capture and green energy usage. The cost of electrolytic aluminum per tonne will increase by $8.3 \%$ and $2.0 \%$, respectively. The decline in the green premium is also mainly due to the decline in the cost of carbon capture and green power energy. By 2060, with development of green electricity, overall carbon emissions will also decline, and the remaining non-electric carbon emissions will decline to a minimal level (see Fig. 7.7). If carbon neutrality is achieved through carbon capture, we estimate that the industry's green premium per tonne will be as low as Rmb262, which is more affordable for aluminum companies. 

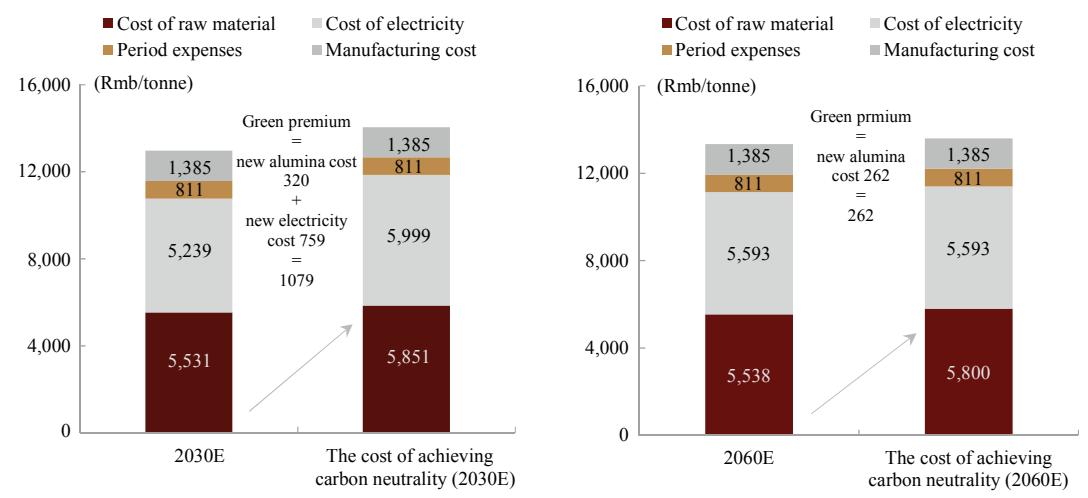

Fig. 7.6 Green premiums for aluminum industry to go carbon neutral through carbon capture in 2030 and 2060. Source Woodmac, Corporate filings, Analysis on the Guidelines for Accounting Methods and Reporting of Greenhouse Gas Emissions of Chinese Aluminum Manufacturers, CICC Research
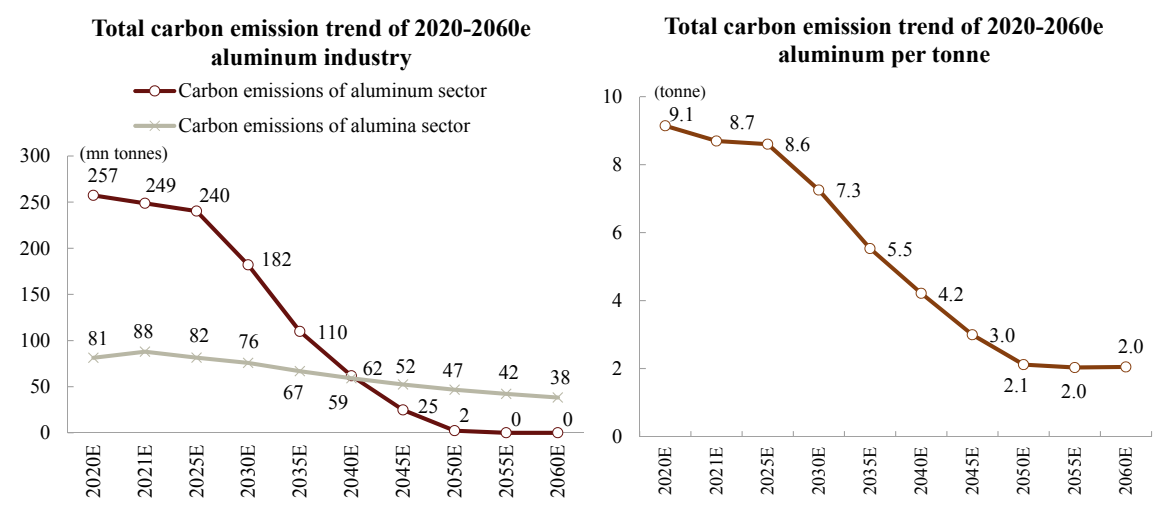

Fig. 7.7 Carbon emissions trend for alumina and aluminum industries in 2020-2060. Source Woodmac, CNKI, tanpaifang.com, CICC Research

\subsection{Chemical Industry: When Carbon Negative Becomes Possible}

\subsubsection{Industry Carbon Emission: Cost for the Chemical Industry to Achieve Carbon Neutrality at the Current Stage}

The chemical industry can be divided into two main fields: Petrochemicals and basic chemicals. In chemical industry, the replacement of naphtha and coal faces substantial pressure from heavy energy consumption in the chemical synthesis process. Looking at the consumption structure of chemical engineering, naphtha and coal consumption in chemical synthesis makes up the most of total consumption. Coal is not only one of 
the main synthetic raw materials, but is also one of the main energy sources. Carbon emissions of general chemical manufacturing mainly come from two processes: (1) energy consumption, including electricity required to operate equipment and steam for production environment; and (2) chemical reaction during the production of chemical products. To take the production of synthetic ammonia as an example of chemical reaction: in the first step of turning coal to gas, one unit of carbon and one unit of $\mathrm{H}_{2} \mathrm{O}$ should theoretically generate one unit of $\mathrm{CO}$ and one unit of $\mathrm{H}_{2}$. But in reality, the transformation cannot be $100 \%$ efficient. If natural gas, coal and oil are used directly as fuels or energy during the process of producing chemicals, that energy may be replaced by green energy. However, if this energy is used as raw materials in chemical reactions, it would be difficult to be replaced. The demand of chemicals will continue to grow along with economic and social development.

The production of synthetic ammonia and methanol accounts for a large proportion of emissions in the chemical industry. Based on China's standards, we estimate that the total carbon emissions of important products such as methanol, synthetic ammonia, ethylene and propylene account for $61 \%$ of total carbon emissions.

Despite sharp divergence among different segments, the overall green premium for the chemical industry is high. We believe that under current conditions, the path for carbon emissions of combining green energy with carbon capture and storage is the most suitable for the industry. Due to the differences in energy consumption and carbon emissions in various reactions, as well as the variations in the cost of carbon capture (Rmb100-420 per tonne) as a result of different $\mathrm{CO}_{2}$ concentration levels, there is large variation in the green premiums for different sub-sectors in the chemical industry. The distance between carbon source and storage location as well as the resources available at the location will also lead to discrepancies in cost of transportation and storage.

At the same time, it is difficult to accurately measure the green premium of all subsectors in the chemical industry. Since methanol, synthetic ammonia, and ethylene account for a large proportion of the production capacity and carbon emissions, and they are also indispensable basic chemical products, we use them as examples to understand the amount of emissions in this industry. We have found that in the three sub-sectors, the path of combining current technology and carbon capture and storage technology is more economically preferable. Our analysis indicates that green premium ratios of chemicals and petrochemicals are $56.9 \%$ and $7.9 \%$, respectively, in 2021. If carbon emissions from electricity consumption are not taken into account, these figures are $53.2 \%$ and $7.4 \%$.

The chemical industry can absorb green premiums internally, but profitability may decline significantly with the current cost to achieve zero carbon. Given the sharp divergence among different segments in this analysis, we use a holistic method to estimate an industry-wide green premium. If the chemical industry reached carbon neutrality in 2019 , total costs would have increased by Rmb250.74bn leading to a $36.7 \%$ industry-wide decline in profit (calculated by "cost of carbon capture multiplied by amount of emission" factoring in electric emissions). According to the National Bureau of Statistics, the total profit of the chemical industry in 2019 was about Rmb683.756bn, and the industry profit would have dropped by $36.7 \%$ after 
carbon neutrality. Even with the high level of profit in 2017, the industry profit after carbon neutrality would still have dropped by $24.4 \%$. If new technologies were to be adopted, the cost of carbon neutrality could not be internalized since new technologies would be immature and expensive. Therefore, we believe the chemical industry could bear the cost of carbon neutrality by fully utilizing carbon capture and storage, but would have resulted in serious decline in profit. Besides, the downward transmission would have caused the cost of terminal infrastructure, consumption and other industries to rise sharply. In the meantime, we need to pay attention to the risk factors brought about by large-scale storage, and it is necessary to improve the feasibility of new technologies by reducing costs.

\subsubsection{Technology Roadmaps for Carbon Emissions Reduction in the Chemical Industry}

Multiple technologies are being used to help the chemical industry achieve net zero or negative carbon emissions. Given the large number of sub-sectors, the chemical industry needs different roadmaps to achieve carbon neutrality. (1) Carbon emissions attributable to electricity and energy consumption needs can be eliminated by outsourcing zero-carbon electricity; (2) Calcium carbide is widely used in current PVC production. As the ethylene method becomes mainstream, demand for calcium carbide products should drop sharply or even fall to zero, leading to carbon neutrality; (3) Carbon capture and storage technology plays an important role in helping the industry reduce emissions. Carbon emissions from coal chemical industries can only be handled through carbon capture given the current technology; (4) Biomass is a high-quality raw material that can help achieve carbon neutrality; (5) Products such as methanol and olefins can be produced through direct synthetic transformation of carbon dioxide and hydrogen. This process has net negative emissions, and the entire process has net zero emissions; and (6) Improving thermal efficiency or reaction efficiency can help achieve energy savings and emissions reduction. In this section, we will discuss the last four technology roadmaps.

Carbon capture and storage technology plays a key role in building a resilient energy system in China with its flexibility and sustainability, and it is especially important in China's coal-dominated energy system.

Use of biomass as raw material has strong potential. Biomass raw materials are mostly renewable and have varied sources. China's total biomass reserves are equivalent to $460 \mathrm{mn}$ tonnes of standard coal (this figure varies sharply based on different studies).

Chemical engineering synthesis with carbon dioxide and hydrogen can replace the current technology and achieve zero carbon emissions. This method uses hydrogen and carbon dioxide to synthesize methanol and gas. For instance, hydrogen from electrolysis of water and carbon dioxide can be directly used to synthesize olefins. This 
process consumes a large amount of carbon dioxide, resulting in negative emissions for the whole process.

Energy conservation and emissions reduction are also important in many subsectors. Through technological upgrading, the amount of raw materials for reaction will be reduced. Technological advancements can also help reduce energy consumption and carbon emissions. Popular methods are: (1) Improving reaction catalyst activity and easing requirements for reaction environment; (2) Introducing energy saving production equipment and other new equipment; and (3) Improving the efficiency of energy regeneration of waste heat.

\subsubsection{Policy Guidance and System Building for Emissions Reduction are Crucial for the Chemical Industry}

Given the numerous sub-sectors, different product markets and complex technological roadmaps, we believe policy guidance is appropriate for the chemical industry.

Carbon tax and carbon trading mechanisms can naturally guide companies to upgrade production methods and reduce energy consumption. With the help of some government restrictions, leading companies with low per unit carbon emissions and companies with advanced production methods will enjoy comparative advantages.

Policy guidance can also encourage innovation by subsidizing new technologies such as zero-carbon biomass and carbon dioxide conversion and utilization technologies. Additional investments in advanced technologies such as advanced electrolytic hydrogen technology and new material innovation projects such as lithium battery materials can reduce the $R \& D$ cost.

Introducing supportive policies to subsidize recycling of chemical products such as PET would also lower production of related products and eventually reduce carbon emissions.

\subsubsection{Lowering the Green Premium: A Feasible Path for Carbon Peak and Carbon Neutrality in the Chemical Industry}

There are various technological approaches to achieving carbon neutrality in the chemical industry. We calculate green premiums of the synthetic ammonia, methanol, and ethylene industries under two roadmaps: (1) Traditional approach plus carbon capture and storage; and (2) $\mathrm{C} 1$ chemical engineering with green hydrogen energy and carbon dioxide as raw materials (including AEC, PEM, SOEC). Both roadmaps can help the industry achieve carbon neutrality.

As shown in Table 7.1, the second approach lowers the green premium more 





significantly. Although both approaches would result in negative green premium, the cost of the second approach would be higher than the first one by 2050, suggesting that new technology may replace the traditional approach by that time. We also reckon that carbon neutral technology without carbon capture is the better approach and deserves the corresponding cost, so the second approach could be implemented gradually before 2050 .

Using previous calculations, we estimate the carbon emissions of the chemical industry. First, we estimate the output growth of the chemical industry. The growth rate will be around $1 \%$ before 2030 and plateau after 2030. Also, the progress in innovation of traditional technology will reduce the carbon emission coefficient by $0.5 \%$ every year. The use of "green hydrogen + carbon dioxide" technology will have an increasing penetration rate of 5\% in 2030 and $70 \%$ in 2060. The penetration rate of substitutional raw materials such as biomass will have a penetration rate of $1 \%$ in 2051 and $10 \%$ in 2056. With carbon capture and storage technology, the chemical industry can reach carbon peak in 2030 and reach emissions of -14 .2bn tonnes in 2060 (see Fig. 7.8).

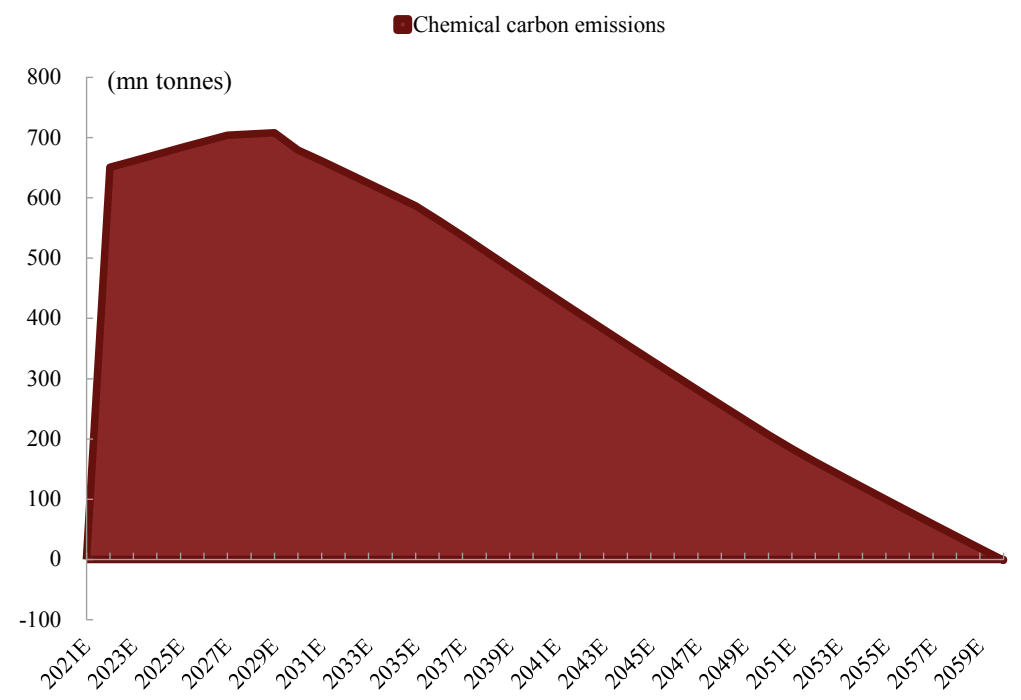

Fig. 7.8 Estimations of carbon emissions of the oil \& gas and chemicals industries in the next 40 years (taking carbon emissions from electricity consumption into account). Note Assuming carbon consumption coefficient is 1.375 for methanol. Carbon consumption coefficient refers to amount of carbon dioxide that can be absorbed by one tonne of product. Source sci99.com, baiinfo.cn, CICC Research 


\subsection{General Manufacturing Industry: Achieving Carbon Peak; Using Clean Energy to Achieve Carbon Neutrality}

\subsubsection{Industry Green Premium: Cost for the General Manufacturing to Achieve Carbon Neutrality at the Current Stage}

The general manufacturing industry accounts for only about $2 \%$ of overall carbon emissions in China. However, the general manufacturing industry involves a wide range of downstream industries, and some production processes and production equipment are highly versatile. Therefore, The R\&D in the general manufacturing sector can play an important role in helping many sectors achieve carbon neutrality.

Carbon emissions from general manufacturing amount to $205 \mathrm{mn}$ tonnes per year, with emissions from electricity accounting for $2.2 \%$ of China's total carbon emissions and $5.7 \%$ of the manufacturing sector's emissions. Electricity consumption contributes $70 \%$ and internal production processes $30 \%$ of total carbon emissions from the sector. In terms of annual contribution, industries with heavier emissions are: Raw coal (128mn tonnes), coke (23mn tonnes), natural gas (22mn tonnes), diesel (8mn tonnes), gasoline ( $6 \mathrm{mn}$ tonnes), other washed coal (4mn tonnes), other gases (4mn tonnes) and coke oven gas ( $1 \mathrm{mn}$ tonne). The top five industries together account for more than $95 \%$ of carbon emissions. Of these, emissions from coal mainly correspond to electricity and emissions from coke mainly correspond to metallurgy. Therefore, reducing power consumption and reducing carbon emissions from metallurgical casting are key to reduce the overall carbon emissions of the general manufacturing industry.

The general manufacturing industry can achieve carbon neutrality through clean energy substitution. Power consumption by general manufacturing accounts for about $70 \%$ of carbon emissions, so it is easy and economical to achieve carbon neutrality by clean energy substitution. Producing green electricity is $11 \%$ more expensive than current hybrid electricity productions. The use of electricity and hydrogen energy are the two main paths for energy consumption and metallurgy. We assume that the cost of achieving carbon neutrality. Overall, the green premium in the general manufacturing industry is Rmb110.60bn.

General manufacturing industries can afford the costs of achieving carbon neutrality. Energy accounts for a relatively low proportion of total cost in general manufacturing industries. According to the previous calculations, if green energy is used to replace fossil energy, the cost of achieving carbon neutrality in the general manufacturing industry is Rmb110.6bn, equivalent to only about $3 \%$ of the industry's profit in 2019. 


\subsubsection{Technology Roadmap for Carbon Emissions Reduction in General Manufacturing Industries}

Carbon emissions in general manufacturing industries mainly come from electricity consumption and metallurgy. In term of electricity consumption, the most suitable way to reduce carbon emissions is to reduce energy use by improving production efficiency. In term of metallurgy, the main way to reduce carbon emissions is to increase the proportion of electrification and improve the original production methods.

Digital transformation can improve production efficiency. Increasing digitization of production equipment and penetration rate of industrial software can help improve production efficiency and energy utilization of manufacturers.

Electric motor systems consume about $75 \%$ of industrial electricity, and highefficiency motors and variable frequency equipment can significantly reduce energy use. High-efficiency motors can reduce energy use by about $20 \%$ on average and variable frequency technology can help cut electricity uses by $30 \%$.

The main source of carbon emissions in metal casting is the smelting copula, for which production is responsible for $53 \%$ of carbon emissions. Through improvements in the casting production process, we think energy consumption per unit of finished product can be reduced by $63.6 \% .^{2}$

Through lightweight and modular design of products, raw materials and energy consumption may be reduced. Equipment refurbishment can also help reduce waste of raw materials, energy use, and carbon emissions.

In term of policy, subsidies can promote the use of new technologies, but require standards and supervision. Complicated subsidy application procedures, loose market regulation, and poorly-designed evaluation standards might have the opposite effect.

Most Chinese general manufacturing companies are small businesses with low profitability. In addition, there are significant differences across different industries. Subsidies and regulation need to be different for different industries and different profit levels.

\subsubsection{Lowering the Green Premium: The Feasible Pathway to Achieving Carbon Neutrality in the General Manufacturing Industry}

The general manufacturing industry already reached peak carbon emissions in 2010 and should achieve carbon neutrality before 2060. According to CAEDs, carbon emissions from general manufacturing industries peaked at $392 \mathrm{mn}$ tonnes in 2010 . Since then, this figure has been falling year-over-year, with 2017 carbon emissions

\footnotetext{
${ }^{2}$ Analysis on Status Quo of Energy Saving and Emission Reduction in the Foundry Industry by Li Yuanyuan et al., 2010.
} 
Table 7.2 Current Green Premium for General Manufacturing Industries ${ }^{3}$

\begin{tabular}{l|c|l|l|l|l|l}
\hline $\begin{array}{l}\text { Energy cost of } \\
\text { general } \\
\text { manufacturing } \\
\text { industries (Rmb } \\
\text { bn) }\end{array}$ & 2019 & $\begin{array}{l}\text { Cost after carbon } \\
\text { neutrality (2019) }\end{array}$ & 2030 & $\begin{array}{l}\text { Cost after carbon } \\
\text { neutrality (2030) }\end{array}$ & 2060 & $\begin{array}{l}\text { Cost after carbon } \\
\text { neutrality (2060) }\end{array}$ \\
\hline Electricity & 118 & 132 & 161 & 161 & 234 & 234 \\
\hline Coke & 22 & 74 & 34 & 53 & 104 & 104 \\
\hline Natural gas & 31 & 31 & 53 & 53 & 147 & 147 \\
\hline Diesel & 18 & 45 & 27 & 32 & 64 & 64 \\
\hline Gasoline & 17 & 35 & 25 & 25 & 49 & 49 \\
\hline Total & 206 & 317 & 301 & 325 & 598 & 598 \\
\hline Green premium & & 111 & & 24 & & 0 \\
\hline
\end{tabular}

Source CEADs, CICC Research

being $40 \%$ lower than the 2010 level. Taking into account the proportion of green electricity, electrification rate of vehicles, the proportion of metallurgical electric furnaces, utilization rate of hydrogen energy, China's economic growth, and energysaving technological advancements, we expect general manufacturing industries to achieve carbon neutrality before 2060 .

Our calculation shows that the green premiums for general manufacturing industries would be Rmb110.6bn, Rmb24.1bn. and Rmb0 in 2019, 2030, and 2060 respectively (see Table 7.2). The main reasons for this decline are electrification of vehicles and falling cost of renewable energy sources and hydrogen.

Open Access This chapter is licensed under the terms of the Creative Commons AttributionNonCommercial-NoDerivatives 4.0 International License (http://creativecommons.org/licenses/bync-nd/4.0/), which permits any noncommercial use, sharing, distribution and reproduction in any medium or format, as long as you give appropriate credit to the original author(s) and the source, provide a link to the Creative Commons license and indicate if you modified the licensed material. You do not have permission under this license to share adapted material derived from this chapter or parts of it.

The images or other third party material in this chapter are included in the chapter's Creative Commons license, unless indicated otherwise in a credit line to the material. If material is not included in the chapter's Creative Commons license and your intended use is not permitted by statutory regulation or exceeds the permitted use, you will need to obtain permission directly from the copyright holder.

\section{() $\Theta \Theta$}

${ }^{3}$ The current green premium for general manufacturing industries is Rmb110.60bn. 